\title{
Identification of RNase-sensitive LINE-1 Ribonucleoprotein Interactions by Differential Affinity Immobilization
}

Hua Jiang ${ }^{1}$, Martin S. Taylor ${ }^{2}$, Kelly R. Molloy ${ }^{3}$, llya Altukhov ${ }^{4}$ and John LaCava ${ }^{1, *}$

\author{
${ }^{1}$ Laboratory of Cellular and Structural Biology, The Rockefeller University, New York, USA; ${ }^{2}$ Department \\ of Pathology, Massachusetts General Hospital, Boston, USA; ${ }^{2}$ Laboratory of Mass Spectrometry and \\ Gaseous Ion Chemistry, The Rockefeller University, New York, USA; ${ }^{4}$ Moscow Institute of Physics and \\ Technology, Dolgoprudny, Russia \\ *For correspondence: jlacava@rockefeller.edu
}

[Abstract] Long Interspersed Nuclear Element-1 (LINE-1, L1) constitutes a family of autonomous, selfreplicating genetic elements known as retrotransposons. Although most are inactive, copious L1 sequences populate the human genome. L1s proliferate in a 'copy-and-paste' fashion through an RNA intermediate; a full-length L1 transcript is $\sim 6,000$ nucleotides long and functions as a bicistronic mRNA that encodes and assembles in cis with two main polypeptides, ORF1p and ORF2p, forming a ribonucleoprotein (RNP); L1 RNPs also interact with a wide range of host factors in positive and negative regulatory capacities. The following protocol describes an approach to affinity enrich ectopically expressed L1 RNPs and, using RNases, release the fraction of protein that depends upon the presence of intact RNA for retention in the immobilized macromolecules.

Keywords: Retrotransposon, LINE-1, L1 RNP, Affinity capture, RNase treatment

[Background] In previous work, an inducible system for the ectopic expression of human L1 in human embryonic kidney (HEK) cells was established. This was achieved by (1) genomically integrating the reverse tetracycline-dependent transactivator (rtTA; Gossen et al., 1995) from the Tet-On Advanced system (Clontech) into the cell line HEK-293T (Dai et al., 2012); the Tet-On modified HEK cell line (referred to originally as HEK-293T-tet-onLD, and subsequently as HEK-293TLD) was then (2) transfected with episomal vectors (pCEP4 series, Invitrogen; Ostertag et al., 2000; An et al., 2009) containing a tetracycline response element promoter (pTRE-Tight, Clontech), which permitted (3) expression of the L1 cassette in response to the presence of doxycycline in the culture medium (Dai et al., 2012; O'Donnell et al., 2013). More recently, we have used this system to study the compositions of affinity isolated L1 RNPs (Taylor et al., 2016)-including the interactomic consequences of treating them with a mixture of RNases A and T1 while immobilized on affinity medium, revealing which proteins become labile upon the treatment compared to a control (Taylor et al., 2013 and 2018). The following protocol, detailed from Taylor et al. (2018), will enable users to obtain affinity enriched L1 RNPs suitable for the aforementioned RNase-sensitivity assay and can be easily adapted to include treatments with various enzymes not specifically described herein. A schematic diagram of the procedure is presented in Figure 1. 


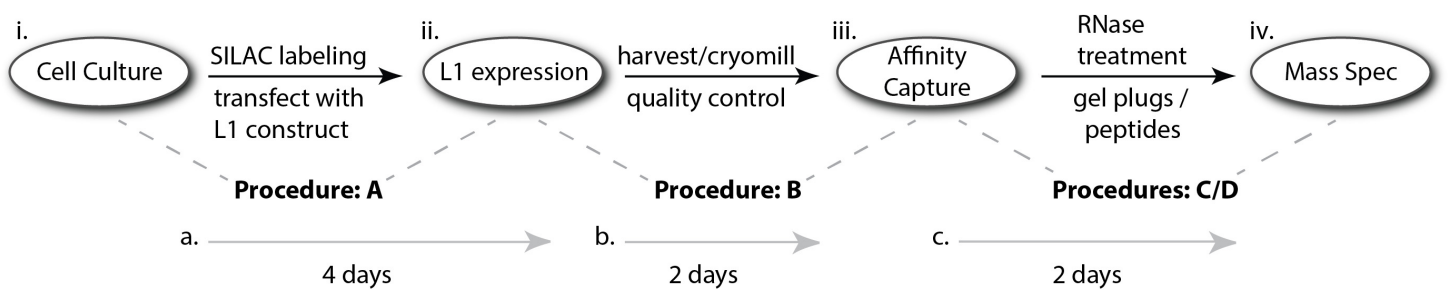

Figure 1. Schematic diagram of this protocol. (i.) Cells will be grown in heavy and light SILAC media and will be transfected with a plasmid supporting (ii.) Inducible, ectopic L1 expression. From the moment the cells reach sufficient density to execute the transfection, (a.) it will be $\sim 4$ more days to harvest and freeze them; this is a natural stopping point in the protocol. These manipulations are described in Procedure A. (b.) An additional $\sim 2$ days will be needed to cryomill the cells to powder and carry out quality control checks by western blot and other protein assays, as well as to complete the peptide workup for mass spectrometry (MS), to determine the degree of heavy SILAC-label incorporation. The MS analysis could be completed as quickly as $\sim 1$ more day if done immediately. These manipulations are described in Procedure B. Pause until thorough SILAC labeling is confirmed. (iii.) Carry out affinity capture, followed by RNase and control treatments; these manipulations are described in Procedure C. (c.) Affinity capture and subsequent peptide workup (described in Procedure D) will require $\sim 2$ days. The time to complete (iv.) MS (Procedure D) and data analysis will depend on the number of samples but could be done within an additional $\sim 3$ days if the experiment is designed exactly as laid out in this protocol. Aside from the LC-MS/MS runs themselves, a substantial portion of the time is occupied by processing the RAW data files in MaxQuant; speed will vary according to the capabilities of the workstation.

To execute this protocol the user requires cryomilled, ORF2p-3xFLAG-tagged, LINE-1-expressing cells. HEK-293T LD cells and inducible tagged L1-expression plasmids may be obtained by request. With respect to the final readout of the below described procedure, RNase sensitivity can be assessed by numerous methods (Taylor et al., 2013 and 2018). Among them, SDS-PAGE and general protein staining provide a way to broadly observe visibly changing bands in gels, and this approach is most useful if the identities of proteins within the bands are known (e.g., labeled entities in Figure 4A). Western blotting provides a targeted and more sensitive way to assess the same, however, validated antibodies against the specific target(s) are required. In contrast, differential quantitative mass spectrometry (MS) provides a sensitive and hypothesis-free mode of analysis (e.g., as in Figure 4D). Quantitative MS for these purposes may be conducted using a wide variety of methods, including the use of metabolic labeling, such as Stable Isotope Labeling by Amino acids in Cell culture (SILAC; Ong et al., 2002), described below, or label-free approaches (such as those reviewed in Armean et al., 2013). 


\section{Materials and Reagents}

Note: Catalog numbers for specific suppliers we use are given for many of the reagents listed below; an equivalent quality reagent from an alternative supplier can typically be substituted with comparable results. If a supplier is not explicitly stated, we do not presume any particular source to be superior. Standard materials and reagents for mammalian cell culture are required and are not all explicitly listed below. For experimental procedures not related to cell culture (for which cell culture grade reagents should be used) molecular biology grade is suitable, unless an alternative is explicitly stated. LC-MS grade reagents are recommended for use in mass spectrometry sample workup. The protocols outlined involve work with liquid nitrogen; appropriate clothing and safety precautions are advised. The NUPAGE denaturing electrophoresis system (Thermo Fisher Scientific) is used in this protocol, but nearly any discontinuous or gradient, denaturing protein SDS-PAGE system will do. Simple solutions are described in this section; solutions containing multiple solutes are defined in the Recipes section, at bottom.

\section{A. Cell culture (Procedure A)}

1. Dialysis Tubing, 3,500 MWCO (Thermo Fisher Scientific, catalog number: 68035)

2. $50 \mathrm{ml}$ polypropylene conical tubes (Thermo Fisher Scientific, catalog number: 339652)

3. 16 Ga needle

4. Luer-lock syringes (various sizes, $10-30 \mathrm{ml}$ )

5. Syringe end caps (Bio-Rad Laboratories, catalog number: 7311660EDU)

6. Styrofoam box

7. Parafilm (Millipore Sigma, catalog number: P7793)

8. Serological pipettes (e.g., from $1 \mathrm{ml}$ to $50 \mathrm{ml}$ )

9. Gloves

10. pLD401 or other LINE-1 expression plasmid

11. Freestyle 293 Medium (Thermo Fisher Scientific, w/o lysine and arginine-custom order)

12. L-glutamine (200 mM; Thermo Fisher Scientific, catalog number: 25030081)

13. L-proline

14. L-arginine

15. L-lysine

16. ${ }^{13} \mathrm{C}_{6}{ }^{15} \mathrm{~N}_{4}$-L-arginine (Arg10; Cambridge Isotope Laboratories, catalog number: CNLM-539-H-PK) 17. ${ }^{13} \mathrm{C}_{6}{ }^{15} \mathrm{~N}_{2}$-L-lysine (Lys8; Cambridge Isotope Laboratories, catalog number: CNLM-291-H-PK)

18. Fetal bovine serum (FBS), tetracycline-free Note: Numerous suppliers can provide this. Many suppliers carry FBS products not labeled as tetracycline-free, but consulting the product specification sheet for a given lot may reveal that tetracycline has been tested for and found to be absent or below a 'negative' threshold (ideally in the single digit $n g / m l$ range). Check with the supplier for the testing threshold and request a certificate of analysis for the lot to be purchased. Test a sample from that specific lot in case of 
doubt. In our hands, the performance of such lots has been identical to 'certified' tetracyclinefree FBS.

19. Hybridoma SFM medium (Thermo Fisher Scientific, catalog number: 12045084)

20. Phosphate-buffered saline (PBS), pH 7.4 (Thermo Fisher Scientific, catalog number: 10010023)

21. PEI (polyethylenimine) Max (MW 40,000; Polysciences, catalog number: 24765-1)

Note: Two grams is enough to transfect $>600 \mathrm{~L}$. To prepare $1 \mathrm{mg} / \mathrm{ml}$ PEI Max working solution:

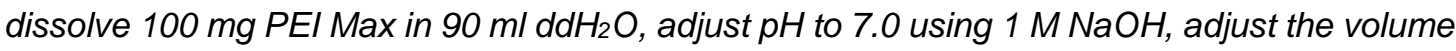
to $100 \mathrm{ml}$, filter sterilize, and store at $4{ }^{\circ} \mathrm{C}$. Never freeze PEI working solution; working solution can be used for up to 6 months if stored at $4{ }^{\circ} \mathrm{C}$.

22. Doxycycline (Millipore Sigma, catalog number: D9891)

Note: Prepare a stock solution of $10 \mathrm{mg} / \mathrm{ml}$ in de-ionized water, sterile filter, and store at $-20{ }^{\circ} \mathrm{C}$, protected from light. Antibiotic stock solutions may lose activity over time; make them fresh at least every six months, but preferably every three (Okerman et al., 2007). Thaw each stock only once; it may be stored a few days at $4{ }^{\circ} \mathrm{C}$ after thawing, and then should be discarded.

23. Liquid nitrogen $\left(\mathrm{LN}_{2}\right)$ and Dewar flask

24. Heavy SILAC medium (see Recipes)

25. Light SILAC medium (see Recipes)

B. Proteomics (Procedures B, C, and D)

Note: For spectrophotometric protein concentration assay, such as the BCA or Bradford assay (Olson and Markwell, 2007), many ready-made kit products for such assays are available.

1. $1.5 \mathrm{ml}$ microcentrifuge tubes (Eppendorf, catalog number: 022363204)

2. $2 \mathrm{ml}$ safe-lock microcentrifuge tubes (Eppendorf, catalog number: 022363344)

3. $5 \mathrm{ml}$ or $15 \mathrm{ml}$ tubes Note: See Step B3e iv for additional considerations regarding microcentrifuge tubes.

4. OMIX C18 pipette tips, 10-100 $\mu$ l (Agilent, catalog number: A57003100)

5. Low binding tubes (e.g., Sorenson, catalog numbers: 11300, 39640T); Eppendorf Protein LoBind, Eppendorf Safe-lock (e.g., Eppendorf, catalog numbers: 145525, 145530)

6. 2-[4-(2-hydroxyethyl)piperazin-1-yl]ethanesulfonic acid (HEPES)

7. Sodium chloride $(\mathrm{NaCl})$

8. Sodium hydroxide $(\mathrm{NaOH})$

9. $\mathrm{NaH}_{2} \mathrm{PO}_{4} \cdot \mathrm{H}_{2} \mathrm{O}$

10. $\mathrm{Na}_{2} \mathrm{HPO}_{4}$

11. Triton $\mathrm{X}-100$

12. Protease inhibitor cocktail, EDTA-free, Roche (Millipore Sigma, catalog number: 11873580001)

13. Ammonium sulfate $\left(\left(\mathrm{NH}_{4}\right)_{2} \mathrm{SO}_{4}\right)$

14. Mono- and di-sodium phosphate

15. Coomassie Brilliant Blue G (Millipore Sigma, catalog number: B0770)

16. Phosphoric acid 
17. Methanol

18. Hydrochloric acid ( $\mathrm{HCl}$; Fisher Scientific, catalog number: A466)

19. Water (LC-MS grade; Fisher Scientific, catalog number: W6500)

Note: Prepare solutions used for mass spectrometry sample workup and analyses with LC-MS grade water and the highest purity reagents available.

20. Acetonitrile (LC-MS grade; Thermo Fisher Scientific, catalog number: 51101)

21. Ammonium Bicarbonate (use highest purity grade available; e.g., Millipore Sigma, catalog number: 022363344)

Note: Prepare $50 \mathrm{ml}$ of a $100 \mathrm{mM}$ solution with LC-MS grade water, filter through a sterile $0.22 \mu \mathrm{m}$ syringe filter, and store at $4{ }^{\circ} \mathrm{C}$ in a clean polypropylene tube. Make fresh every couple weeks.

22. Trypsin Gold, Mass Spectrometry Grade (Promega, catalog number: V5280)

Note: Prepare trypsin stock solution at $100 \mathrm{ng} / \mu \mathrm{l}$ in $1 \mathrm{mM} \mathrm{HCl}$; store in aliquots of up to 20-50 $\mu \mathrm{l}$ at $-80^{\circ} \mathrm{C}$.

23. Trifluoroacetic Acid (TFA) (sequencing grade, or better; e.g., Thermo Fisher Scientific, catalog number: 28902)

Note: Produce a 20\% W/V TFA stock with LC-MS grade water.

24. Acetic Acid (Fisher Scientific, catalog number: 60-046-912)

25. (Optional) Antibodies for Western blotting

Note: Commercially available antibodies that we have used with success to identify ORF1p and ORF2p-3xFLAG by Western blotting.

a. a-ORF1p, clone $4 \mathrm{H} 1$ (Millipore Sigma, catalog number: MABC1152), primary antibody, titer-1:5,000 (original concentration $2 \mathrm{mg} / \mathrm{ml}$; final concentration $0.4 \mu \mathrm{g} / \mathrm{ml}$ )

b. Anti-FLAG M2 antibody (Millipore Sigma, catalog number: F3165 or F1804), primary antibody, titer-1:2,000 (original concentration $1 \mathrm{mg} / \mathrm{ml}$; final concentration $0.5 \mu \mathrm{g} / \mathrm{ml}$ )

c. a-mouse IgG, HRP-linked whole antibody (GE Healthcare, catalog number: NA931-1ML), secondary antibody for enhanced chemiluminescence, titer-1:10,000.

26. Anti-FLAG M2 antibody (Millipore Sigma, catalog number: F3165 or F1804)

27. Dynabeads M-270 epoxy (Thermo Fisher Scientific, catalog number: 14302D)

28. Glycerol

29. Bovine Serum Albumin (BSA; Standard Ampules, $2 \mathrm{mg} / \mathrm{ml}$, Thermo Fisher Scientific, catalog number: 23209)

30. $1 \mathrm{M}$ iodoacetamide stock solution

Note: Best practice is to prepare iodoacetamide in water, fresh; iodoacetamide is light sensitive and chemically labile. In our experience, $1 \mathrm{M}$ aliquots can be stored at $-20^{\circ} \mathrm{C}$, protected from light, and are still functional for several months.

31. RNase A/T1 Mix (Thermo Fisher Scientific, catalog number: EN0551)

32. 4x LDS (lithium dodecyl sulfate) sample loading buffer (Thermo Fisher Scientific, catalog number: NP0007) 
33. 10x sample reducing agent (Thermo Fisher Scientific, catalog number: NP0004); or $500 \mathrm{mM}$ dithiothreitol (DTT)

34. 4-12\% Bis-Tris gels, 10-well, $1 \mathrm{~mm}$ (Thermo Fisher Scientific, catalog number: NP0321BOX) Note: Sample volumes loaded as described here may be up to 60-70 $\mu \mathrm{l}$ in volume, exceeding the standard well capacity. Thus, each sample is loaded twice (described in Step D4). After the first loading the sample is run just into the gel, and then the remainder is loaded into the same well and the run is completed. Alternatively, gels with sufficient well capacities for a single loading may be used, such as Bolt 4-12\% Bis-Tris Plus Gels, 10-well, $1 \mathrm{~mm}$ (Thermo Fisher Scientific, catalog number: NPNW04120BOX).

35. 20x MOPS (3-morpholinopropane-1-sulfonic acid) gel running buffer (Thermo Fisher Scientific, catalog number: NP0001)

36. 10x PBS stock solution (see Recipes)

37. $0.1 \mathrm{M}$ sodium phosphate $\mathrm{pH} 7.4$ (see Recipes)

38. $3 \mathrm{M}$ Ammonium sulfate (see Recipes)

39. Magnetic Media Storage Solution (see Recipes)

40. Protein extraction solution (see Recipes)

41. Gel acidification solution (see Recipes)

42. Blue Silver stain (see Recipes)

43. Gel plug destaining solution (see Recipes)

44. Tip wetting solution (see Recipes)

45. Tip wash solution (see Recipes)

46. Elution 1 solution (see Recipes)

47. Elution 2 solution (see Recipes)

\section{Equipment}

Note: Typical molecular biology lab equipment is required, not all explicitly listed below. catalog numbers are given for most of the equipment as examples; instruments from alternative manufacturers may be substituted provided equivalent functionality. Equipment has been listed approximately in order of use.

A. Cell culture (Procedure A)

1. Pipettes

2. $\mathrm{CO}_{2}$ incubator for mammalian cell culture

3. Scalpels (e.g., size 11) or razor blades

4. New Brunswick Innova 2000 platform shaker (Eppendorf, catalog number: M1190-0002; or Thermo Fisher Scientific, model: Forma Model 416; or equivalent)

Note: Any shaker installed in a mammalian cell culture incubator must be able to tolerate continuous high humidity ( $\sim 90 \%$ relative humidity).

5. Swing-bucket centrifuge rotor 
6. $1 \mathrm{~L}$ square PYREX glass bottles (Corning, catalog number: 1396-1L) Note: Plastic bottles inhibit transfection (polypropylene, polyethylene, PETG)

7. Erlenmeyer flasks

8. Ice bucket

9. Hemocytometer

10. High speed centrifuge with appropriate rotor for pelleting cells from large volumes (e.g., for $\sim 250$ or $500 \mathrm{ml}$ bottles)

B. Proteomics (Procedures B, C, and D)

1. Metal spatula

2. Milling balls, stainless steel, $20 \mathrm{~mm}$ (Retsch, catalog number: 05.368.0062)

3. $50 \mathrm{ml}$ stainless steel milling jar (Retsch, catalog number: 01.462.0149)

4. PTFE milling jar insulator (custom made, see LaCava et al., 2016) Note: The use of a jar insulator is optional, but strongly recommended.

5. Planetary Ball Mill PM 100 (Retsch, model: PM 100, catalog number: 20.540.0001)

6. Vacuum centrifugal concentrator (a.k.a. speed-vac)

7. Neodymium magnet microfuge tube rack (Thermo Fisher Scientific, catalog number: 12321D)

8. Thermomixer (Eppendorf, catalog number: 5355000.011; or equivalent)

9. Refrigerated microcentrifuge (capable of reaching $\sim 20,000 \mathrm{RCF}$ )

10. Microtip sonicator (e.g., Qsonica, model: Q700) equipped with a low intensity 1/16" microtip probe (Qsonica, catalog number: 4717)

11. SDS-PAGE electrophoresis system (e.g., Thermo Fisher Scientific NuPage)

12. Gel knife or chisel

13. Orbital shaker

14. Low-extractable borosilicate glass vials with chemically resistant caps (e.g., Kimble, catalog number: 74515-20)

Note: These are recommended for the storage of stock and working solutions used for MS.

15. Quadrupole-Orbitrap mass spectrometer (Thermo Fisher Scientific $Q$ Exactive or Fusion series) interfaced with a nano-flow liquid chromatography (LC) system (e.g., Thermo Scientific EASYnLC 1200 or UltiMate 3000 RSLCnano)

Note: Older model LC-MS systems may also be perfectly suitable; at the time this analysis was initiated we were using LTQ-Orbitrap models, see Step D7.

\section{Software}

1. MaxQuant

2. (Optional) $\mathrm{R}$ 


\section{Procedure}

The protocol below anticipates that suspension-grown, SILAC-labeled cells will be used to enable a final readout by quantitative MS. In the case that SILAC labeling is not necessary for your experimental design, effective standard procedures for L1 expression in HEK-293TLD cells are thoroughly described in Taylor et al., 2016; review of this reference is recommended in any case. In the case that adherent cells will be SILAC labeled, see Taylor et al., 2013.

A. Express ORF2p-3xFLAG-tagged L1 in SILAC labeled HEK-293TLD suspension cultures SILAC-labeled cells will be transfected in suspension using pLD401 plasmid DNA, and/or other 3xFLAG-tagged constructs such as pMT302 (Taylor et al., 2013), and PEI (polyethylenimine); after transfection, L1 expression will be induced by the addition of doxycycline (Dox; typically $1 \mu \mathrm{g} / \mathrm{ml}$ ). High-quality endotoxin-free DNA is critical to success. pLD401 contains a synthetic, recoded human L1 sequence (Orfeus-Hs) encoding a carboxy-terminal 3xFLAG-tagged ORF2p, expressed under the control of the tetracycline response element promoter (An et al., 2011; Taylor et al., 2013). Suspension culture yields large human cell pellets with minimal work, waste, and cost when

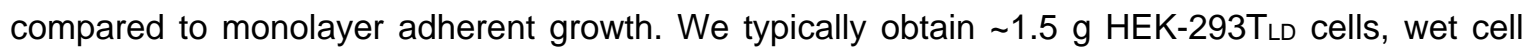
weight, per $100 \mathrm{ml}$ culture. In the past we have used square Corning Pyrex bottles in an orbital platform shaker at $130 \mathrm{rpm}$, installed inside of a $37^{\circ} \mathrm{C}$, humidified incubator, maintained at $5 \%-8 \%$ $\mathrm{CO}_{2}$ (Muller et al., 2005; Taylor et al., 2016; Domanski and LaCava, 2017); however, more recently we have obtained comparable results using Erlenmeyer flasks at the same speed. For instructions on setting up the hardware for such a system, refer to Taylor et al., 2016. In addition to procedures we describe, standard mammalian cell culturing techniques and best practices apply (Freshney, 2011; Uphoff and Drexler, 2013).

If starting from adherent HEK-293TLD cells, follow the HEK cell suspension adaptation protocol presented in Domanski and LaCava, 2017; however, unlike the cells described in that procedure, frozen stocks made from suspension-adapted HEK-293TLD cells can be used to directly inoculate new suspension cultures successfully. If starting from a frozen stock or recently suspensionconditioned HEK-293TLD cells, proceed as detailed below. Cells may grow to a density of $\sim 10 \mathrm{million} / \mathrm{ml}$ but growth slows after $\sim 5 \mathrm{million} / \mathrm{ml}$ and transfection efficiency drops when cells are not in logarithmic growth.

IMPORTANT: We have observed that, over time, the Dox-inducibility of HEK-293TLD can markedly decline. This has been determined to be caused by loss of expression of rtTA. Therefore, these cells should be periodically re-selected for blasticidin resistance (the BSD gene [Kimura et al., 1994]) was co-incorporated with rtTA), ensuring a transcriptionally active rtTA locus. Although keeping cells under continuous selection is the surest way to ensure a maximally Dox-responsive cell population, cells selected prior to making frozen stocks respond in sufficient proportion and uniformity for the work described below; it is also gentler on the cells overall. We therefore periodically re-select HEK293T LD cell populations under challenge of $10 \mu \mathrm{g} / \mathrm{ml}$ blasticidin S prior making stocks, but do not maintain cells under continuous selection. 
Practical note: Before proceeding to full-scale expression in SILAC medium, we recommend optimization experiments in standard medium to verify transfection efficiency and Dox induction response within your setup and implementation. We recommend parallel transfections with a TetOn GFP plasmid and a constitutively active GFP plasmid, with DNA prepared at the same time and in the same method as the pLD401 plasmid to be transfected. The ratio of PEI-max to DNA may be varied along with other parameters, see Longo et al., 2013; Stuible et al., 2018. Prior to culturing cells in suspension at full-scale, it may also be helpful to compare the per-cell expression of ORF1p and/or ORF2p to that of cells grown in adherent cultures, transiently transfected with either PEI-max or a commercial cationic lipid-based reagent, maintaining other variables comparably to suspension culture. Proper suspension culture produces indistinguishable per-cell expression from adherent culture transfected with either method (see Taylor et al., 2018, Appendix 1-Figure 1).

1. Prepare heavy and light SILAC media (see Recipes).

a. Dialyze Tet-free FBS to remove amino acids for $24 \mathrm{~h}$, at $4{ }^{\circ} \mathrm{C}$, against 10 -volumes of PBS with 2 buffer changes using 3500 MWCO dialysis tubing.

Example: $500 \mathrm{ml} F B S$, dialyzed against 5 L PBS starting at noon (Day 1). Before leaving the lab in the evening change the buffer ( 5 fresh PBS). First thing the next morning (Day 2) change the buffer again; retrieve dialyzed FBS $\sim$ noon. For this regime, it is helpful to have two $10 \mathrm{~L}$ buckets.

b. For 'heavy' SILAC medium use Arg10 and Lys8; for 'light' SILAC medium instead use naturally occurring L-arginine and L-lysine.

c. Sterilize the media by filtration.

2. Inoculate otherwise identical heavy and light SILAC suspension cultures at a cell density of $\sim 0.2$ million cells per $\mathrm{ml}$ in $200 \mathrm{ml}$.

3. Grow to $\sim 5 \mathrm{million} / \mathrm{ml}$.

Obtaining accurate cell counts can be challenging because HEK-293TLD tends to grow in small clumps of up to $\sim 30$ cells in suspension. Accurate counting requires dissociation of the clumps by gentle trituration using a pipette.

i. Using a $1 \mathrm{ml}$ Serological pipette, aliquot $200 \mu \mathrm{l}$ of culture to a clean microcentrifuge tube.

ii. Mix by flicking, and pipette $10 \mu \mathrm{l}$ onto one side of the hemocytometer (also called hemacytometer).

iii. With a $200 \mu \mathrm{l}$ pipette, set the volume to $\sim 150 \mu \mathrm{l}$ and triturate 30 times to break up clumps. Try not to foam.

iv. Pipette $10 \mu \mathrm{l}$ onto the remaining half of the hemocytometer.

v. Visualize the cells before and after cell clump dissociation by trituration. Shearing during trituration may lyse a small fraction of the cells. Increase or decrease trituration if appropriate to get accurate cell counts with minimal lysis. Properly triturated samples can also be counted in automated cell counters and leverage vital stains.

4. Passage these cells, which have now doubled $\sim 5$ times, inoculating into fresh heavy and light SILAC suspension cultures at a cell density of $\sim 0.2 \mathrm{million} / \mathrm{ml}$ in $200 \mathrm{ml}$. 
IMPORTANT: From the time of seeding cells in SILAC suspension, until the time of harvesting, the cells should have been permitted to double $\geq 10$ times to assure thorough Arg10/Lys8 metabolic labeling of the proteome. Following the scheme presented here starting from Step A2, above, through Step A8, below, assures 11 doublings. Additional passages prior to induction, if convenient, provides similar results.

5. Grow to $\sim 2.5 \mathrm{million} / \mathrm{ml}$ in $200 \mathrm{ml}$ medium ( $\sim 4$ doublings). We have successfully transfected at up to $4 \mathrm{million} / \mathrm{ml}$ but recommend this concentration to ensure logarithmic growth.

6. On Day 1-transfect the cells in suspension

Each $200 \mathrm{ml}$ suspension culture will receive $1 \mu \mathrm{g} / \mathrm{ml}$ pLD401 DNA and $3 \mu \mathrm{g} / \mathrm{ml}$ PEI 'Max' $40 \mathrm{kDa}$, prepared in $-1 / 20^{\text {th }}$ the final culture volume hybridoma SFM medium. A master transfection mix for the two cultures is made. The following example assumes $2 \times 200 \mathrm{mI}$ SILAC cultures-one heavy, one light-and transfection with pLD401 (ORF2p-3xFLAG). If working with a larger number, scale up accordingly. A parallel GFP plasmid may be used as a control for transfection efficiency, we recommend a Tet-On plasmid (in which case, add $1 \mu \mathrm{g} / \mathrm{ml}$ Dox to the control GFP culture at the time of transfection).

a. Warm $20 \mathrm{ml}$ hybridoma-SFM medium to room temperature, $10 \mathrm{ml}$ hybridoma-SFM per $200 \mathrm{ml}$ culture to be transfected.

b. Add $400 \mu \mathrm{g}$ pLD401 to the hybridoma-SFM and mix well, e.g., by vortexing.

c. Add $1.2 \mathrm{ml}$ of $1 \mathrm{mg} / \mathrm{ml}$ PEI Max ( $\mathrm{pH}$ 7.0) to the hybridoma-SFM/DNA solution and mix well. Final volume should be $\sim 22-23 \mathrm{ml}$.

d. Incubate for $15 \mathrm{~min}$ at room temperature to allow DNA-PEI complexes to form.

e. Pipette half of the transfection mixture into each $200 \mathrm{ml}$ culture and return to the incubator.

7. On Day 2-split cells 1:2.5-1:3

Transfer half $(100 \mathrm{ml})$ of each transfected SILAC suspension culture to each of two $1 \mathrm{~L}$ bottles containing 150-200 ml of fresh SILAC medium, resulting in $2 \times 250 \mathrm{ml}$ or $2 \times 300 \mathrm{ml}$ cultures for both heavy and light.

Note: If desired, before the decision to split the cells and use more SILAC media, check the efficiency of the GFP control transfection culture.

8. On Day 3-induce each culture by addition of dox at a final concentration of $1 \mu \mathrm{g} / \mathrm{ml}$.

The cell density at the time of induction should be $\sim 4 \mathrm{million} / \mathrm{ml}$ ( $\sim 2$ doublings, constituting $\sim 11$ total doublings to this point). Dilute accordingly or wait an additional day if needed. L1 expression should be induced for $\sim 24 \mathrm{~h}$, by $48 \mathrm{~h}$, ORF2p expression declines (Taylor et al., 2013); shorter induction times may be sufficient but should be verified.

9. On Day 4-harvest cells by centrifugation and extrude into liquid nitrogen.

a. Count cells; counts are useful for normalization and blotting.

b. Gather an ice bucket and clean centrifuge bottles.

c. Transfer a $1 \mathrm{ml}$ aliquot(s) of each culture for Western blotting to a microcentrifuge tube. Spin at $\leq 1,000 \mathrm{RCF}$ for $30 \mathrm{~s}$, aspirate the media, and store on ice until freezing is convenient. 
IMPORTANT: Check for comparable levels of ORF1p and ORF2p-3xFLAG expression in heavy and light labeled cell cultures by Western blot (antibodies and titers described in Materials and Reagents B25). If the expression levels are very different (greater than $\pm 20 \%$ ), the samples may not be suitable for quantitative comparisons or will require thoughtful normalizations.

d. Spin the cultures at $\leq 1,000 \times \mathrm{g}$ for $10 \mathrm{~min}$ at $4{ }^{\circ} \mathrm{C}$ to pellet.

This can be done in several $50 \mathrm{ml}$ conical tubes for each batch, or in fewer, larger bottles. Note: The pellets should appear approximately uniform. If centrifuged too hard, cells will be crushed, forming two different-colored layers. The goal here, and in subsequent centrifugations of these cells, is to obtain a relatively tight-packed cell pellet that maximally excludes buffer without breaking the cells. We consider 1,000 $x \mathrm{~g}$ to be the maximum nominal centrifugal force to be used. We are commonly using a Sorvall T6000D or Beckman Allegra $X-14 R$ with swing-bucket centrifuge rotor at 2,000 rpm ( 830-930 $\times$ g). One may want to establish their choice operating speeds in a preliminary experiment.

10. Resuspend the pellets in a minimal volume of PBS (approximately equal volume to the pellet) using a $25 \mathrm{ml}$ pipette set to 'slow.' One may pool resuspended cells.

Note: Additional washes may be added if needed; however, we attempt to limit the amount of handling before freezing. Moreover, one may choose to handle the cells obtained from each suspension culture separately, e.g., in case of potential differences in metabolic labeling efficiency (see below), transfection, or Dox induction efficiency between cultures. Powders produced from similar cell populations may be mixed after milling and quality control (Procedure $B$ ) if desired; when kept separate, each culture represents a biological replicate. On the other hand, pooling is often advantageous for sample handling and may be done at this point.

11. Pellet cells inside syringes.

a. Select syringe(s) for cell pelleting. Syringes with capacities in the range of 10-30 $\mathrm{ml}$ are typically appropriate for suspension culture yields.

b. Remove the plungers and set aside.

c. Securely cap syringes with Luer-lock end caps at spout, Parafilm at plunger opening, and place inside $50 \mathrm{ml}$ conical tubes.

d. Spin at $\leq 1,000 \times g$ for $10 \mathrm{~min}$ at $4{ }^{\circ} \mathrm{C}$. Transfer syringes to an ice bucket.

i. During the centrifugation, insert a conical tube rack in a Styrofoam box. Fill the box with $\mathrm{LN}_{2}$ to at least the mid-point of the rack.

ii. Pre-label $50 \mathrm{ml}$ conical tubes. Punch a number of holes in the caps of the tubes using a $16 \mathrm{Ga}$ needle. This will permit the $\mathrm{LN}_{2}$ to be drained from the tubes later without loss of cell material. These caps will later be replaced with un-punched caps. To avoid plastic waste, punch caps taken from used $50 \mathrm{ml}$ conical tubes destined for disposal (wash caps first) and save punched caps for future use. Each tube will hold approximately 15$20 \mathrm{~g}$ extruded cells, which we often refer to as 'BBs' because of their round shape.

iii. Transfer the pre-labeled tubes to the rack in $\mathrm{LN}_{2}$. Fill the tubes with $\mathrm{LN}_{2}$. 
e. Aspirate the PBS, leaving only the wet cell pellet in the syringe.

12. Extrude the cells into the $\mathrm{LN}_{2}$ as follows. Remove the Luer lock cap. Positioning the bottom of the syringe over the $50 \mathrm{ml}$ conical tube with $\mathrm{LN}_{2}$, insert the syringe plunger carefully. Extrude the cells gradually into the tube containing $\mathrm{LN}_{2}$. If injected too fast, they will form large clumps. If more $\mathrm{LN}_{2}$ is needed, carefully pour more in. Use the pre-chilled spatula as needed to break apart any clumps.

13. Wearing appropriate protective gloves, cap the tube using the punched lid. Pressure may build up and cause $L N_{2}$ to spurt out through the punches. Exercise caution.

14. Decant $L N_{2}$ into dewar or Styrofoam box and replace the punched lid with an intact lid. Store the tubes at $-80^{\circ} \mathrm{C}$ until cryomilling.

B. Cryomill L1-expressing HEK-293TLD cells and conduct quality control checks

1. Cryogenically disrupt the cell pellets Cryo-milling L1 expressing HEK-293TLD cells has been previously described in intricate detail, see LaCava et al., 2016; Taylor et al., 2016. Briefly:

a. Pre-cool an insulator, milling jar, $2 \times 20 \mathrm{~mm}$ grinding balls, a metal spatula, and a $50 \mathrm{ml}$ tube by immersing in $\mathrm{LN}_{2}$.

b. Place the cell pellets inside the jar, jar inside the insulator, and assembly inside the Retsch PM 100 milling apparatus.

c. Set the counter balance and clamp the jar in place. Run the machine for 3 milling cycles of 3 min each (reverse rotation, 1 min interval, no break time) at $400 \mathrm{rpm}$.

d. Cool down the milling jar with $\mathrm{LN}_{2}$ between cycles.

e. Recover the resulting cell powder using a spatula and transfer to $50 \mathrm{ml}$ tube. Store at $-80^{\circ} \mathrm{C}$.

2. Assess the comparability of the cell powders by protein content

Extract 25-50 mg of each cell powder into 9 parts (225-450 $\mu$ l) protein extraction solution (see immediately below) and check by protein assay that each yields a similar protein content (typically $\pm 10 \%$ ). Extracts may be produced more dilute if greater volume is advantageous. Save $10 \mu \mathrm{l}$ for checking heavy amino acid incorporation (Step B3, below). The procedure essentially follows the rationale laid out in Shevchenko et al., 2006.

a. Combine cell powder with your favorite protein extraction solution (e.g., what you may use for immunoprecipitation-see Recipes), vortex (and if necessary, briefly sonicate as per Step C2f) to homogenize, and then centrifuge the extract for $10 \mathrm{~min}$ at $20,000 \times \mathrm{g}$ to produce a clarified extract that can be measured by e.g., Bradford or BCA assays.

b. Alternatively, extract proteins in a Tris-buffered solution containing $2 \%(w / v)$ SDS and measure protein content by BCA assay-SDS is not well tolerated by the Bradford assay (Zor and Selinger, 1996). SDS-based solutions tend to produce viscous cell extracts requiring a greater degree of sonication than typical IP solutions. 
IMPORTANT: If comparable protein quantities are obtained from similar masses of cell powder, future experiments and comparisons may be calibrated to the mass of powder extracted. If the respective yields of protein from heavy and light SILAC cell powders made under identical extraction conditions are not comparable, then one source of material may have retained more liquid in the cell pellet before extrusion into $L N_{2}$ (i.e., incomplete PBS removal) or may have accumulated excessive condensate due to storage at $-80{ }^{\circ} \mathrm{C}$ with an improperly closed cap. Additional water weight will reduce the apparent yield of protein per $\mathrm{mg}$ of cell powder. In this case, future IP experiments using those materials should be calibrated by relative protein content per mass of powder.

3. Assess the percentage of heavy amino acid incorporation.

IMPORTANT: In order to make quantitative comparisons by mass spectrometry using SILAC methods, heavy SILAC labeling should be thorough, $\sim 95 \%$ or better. Provided (a) the heavy SILAC proteome is thoroughly labeled with Arg10 and Lys8, and both (b) target protein expression, as assessed by Western blotting (done in Step A9c, above), as well as (c) protein content per mass of cell powder, as assessed by e.g., a colorimetric assay (Step B2, above), are both in good agreement between heavy and light materials, then these materials are ideal for quantitative mass spectrometry work.

a. Conduct SDS-PAGE of clarified cell extracts from heavy-labeled cells.

i. Add DTT to $25 \mathrm{mM}$ to the $10 \mu \mathrm{l}$ sample(s) (Step B2a) and heat at $70^{\circ} \mathrm{C}$ for $10 \mathrm{~min}$, and then briefly chill samples on ice.

ii. Add iodoacetamide to $100 \mathrm{mM}$ and incubate at room temperature for $30 \mathrm{~min}$ in the dark.

iii. Load a range of aliquots-e.g., 1, 2, and $4 \mu \mathrm{l}$ or 3 and $6 \mu \mathrm{l}$-on e.g., a 10-well, $1 \mathrm{~mm}$, $4-12 \%$ Bis-Tris gel.

Notes:

1) Loading a range ensures the likely production of gel plugs with an appropriate quantity of protein, despite variations in extract efficiency, etc.

2) Typical liquid chromatography columns attached to mass spectrometry systems have loading capacities of $\sim 1 \mu \mathrm{g}$. In our hands, loading $1 / 2$ the peptides ultimately obtained from a $4 \mu \mathrm{l}$ aliquot of extract and following the handling procedures described here, only approaches $\leq 20 \%$ of the column capacity upon loading. This is sufficient to estimate the $\mathrm{H}$-label incorporation. More material may be loaded at the user's discretion.

iv. Electrophorese the samples until they migrate $\sim 6 \mathrm{~mm}$ into the gel as assessed by gel loading dye at the sample migration front.

b. Fix and Coomassie stain the gel.

i. We use 'blue silver' (see Recipes), with the following modified pre-washing procedure for NuPAGE Bis-Tris gels. All steps that follow are carried out at room temperature until otherwise stated. 
1) After opening the gel cassette, with the gel adhered to one of the plates, use a clean gel knife/chisel to trim away the wells and the portion of the gel below the $6 \mathrm{~mm}$ mark (readily discerned by the position of the loading-dye front).

2) Transfer the upper portion of the gel from the plastic cassette to a clean plastic $15 \mathrm{~cm}$ diameter petri dish and incubate for $10 \mathrm{~min}$ in $40 \mathrm{ml}$ of de-ionized water with gentle agitation on an orbital shaker.

3) Remove the water and replace it with $40 \mathrm{ml}$ of $0.1 \mathrm{M} \mathrm{HCl}$; incubate for $10 \mathrm{~min}$.

4) Remove the $0.1 \mathrm{M} \mathrm{HCl}$ and replace it with $40 \mathrm{ml}$ of water; incubate for $10 \mathrm{~min}$.

5) Remove the water and replace it with $40 \mathrm{ml}$ of blue silver stain; incubate for $2 \mathrm{~h}$ to overnight. If the gel has been properly washed in the prior 3 steps, the blue silver will remain a deep, translucent green color due to maintenance of the low $\mathrm{pH}$ dye solution. If the washing is incomplete, residual buffering capacity within the gel may turn the stain blue-ish, and/or, the gel may develop uneven background staining. Changing the stain and incubating several hours to overnight in fresh (green-hued) blue silver will typically resolve this problem and result in mild, uniform background staining with major bands clearly visible above background.

ii. Destain background thoroughly-several hours to overnight.

1) For blue silver, simply use several changes of de-ionized water.

2) You may choose to take an image of the gel. Always clean surfaces used to image gels that will contribute sample to mass spectrometry analyses.

c. Cut the regions of gel containing the samples from just below the well to just above the dye front (referred to as a 'gel plug;' will appear similar to those depicted in Figure 4C, but more protein rich)-Day 1.

Note: If extracted 1:9 as suggested in Step B2a, the 2 or $4 \mu$ l samples should contain a sufficient quantity of protein for this analysis. The gel should be cut upon a clean surface. We use a rectangular glass plate placed over white paper, which aids visibility of the gel and its pieces. Solutions used below should be prepared with 'mass spectrometry' grade reagents.

i. Using a clean razor blade or scalpel, chop each one into $1 \mathrm{~mm}^{3}$ cubes (about 25 pieces per gel plug), and transfer to a $1.5 \mathrm{ml}$ microfuge tube.

Note: The blade may be cleaned of residual gel fragments when necessary by agitating it in a beaker of molecular biology grade water; residual liquid can be wicked away by touching the tip of the blade to a clean low-lint tissue ('Kimwipe').

ii. Add $500 \mu \mathrm{l}$ of 'gel plug destaining solution' to the gel pieces in the tubes (50 mM ammonium bicarbonate in $50 \%(\mathrm{v} / \mathrm{v})$ acetonitrile; see Recipes).

iii. Mix with the gel pieces by vortexing.

Note: If the color of the solution changes to dark blue immediately, discard it and add another $500 \mu \mathrm{l}$ of destaining solution. One milliliter may be used here instead of $500 \mu$;; repeat multiple times if the solution becomes blue quickly. 
iv. Incubate at $37^{\circ} \mathrm{C}$ for $1 \mathrm{~h}$ with shaking in a Thermomixer (1,000-1,200 rpm); discard the supernatant. The gel pieces should be in motion, not settled at the bottom of the tube.

v. Add another $500 \mu \mathrm{l}$ of destaining solution if the gel pieces are still blue. Note: Continue to destain as needed (this step can go overnight).

vi. Remove destain when the gel pieces no longer exhibit blue staining. Note: They should appear whitish and semi-transparent with no obvious blue remaining.

vii. Dehydrate gel pieces with $500 \mu \mathrm{l}$ acetonitrile, vortex, let the tubes sit at room temperature for 2 min or more.

Note: Gel pieces will appear opaque and thoroughly white.

viii. Remove acetonitrile from all samples.

ix. Dry samples in a vacuum centrifuge ('speed-vac') for $10 \mathrm{~min}$.

x. Samples can be stored at $-20^{\circ} \mathrm{C}$ or proceed to trypsin digest.

d. In-gel digestions of proteins to peptides using trypsin-Day 2.

i. Prepare all tubes on ice.

ii. Prepare trypsin working solution: $12.5 \mathrm{ng} / \mu \mathrm{l}$ in $50 \mathrm{mM}$ ammonium bicarbonate. Our trypsin stock is $100 \mathrm{ng} / \mu \mathrm{l}$ in $1 \mathrm{mM} \mathrm{HCl}$.

iii. Add enough $12.5 \mathrm{ng} / \mu \mathrm{l}$ trypsin to cover the gel pieces.

Note: This will vary by gel plug dimensions, but in our experience is $\sim 38 \mu l$ for gel plugs obtained from 15-well, $1 \mathrm{~mm}$ thickness NuPAGE gel, and -90 $\mu \mathrm{l}$ for a 10-well gel of the same.

iv. Let samples swell for $45 \mathrm{~min}$ on ice.

v. After swelling, add $50 \mathrm{mM}$ ammonium bicarbonate to cover gel pieces if necessary. Note: Typically, $\sim 12 \mu \mathrm{l}$ for 15-well or $\sim 30 \mu \mathrm{l}$ for 10-well, $1 \mathrm{~mm}$ thickness gel plug.

vi. Move the tubes to a $37^{\circ} \mathrm{C}$ incubator to digest overnight (or at least $6 \mathrm{~h}$ ).

e. Terminate the digest; collect and pool the peptides-Day 3.

i. Produce aliquots of $2 \%$ and $0.1 \%(\mathrm{w} / \mathrm{v})$ TFA from the $20 \%$ stock.

ii. Add $1 / 3^{\text {rd }}$ the digestion volume of $2 \%(\mathrm{w} / \mathrm{v})$ TFA to the digestion mix $(0.5 \% \mathrm{w} / \mathrm{v}$ TFA final concentration) to stop digestion.

iii. Incubate at room temperature for $5 \mathrm{~min}$ with shaking in a Thermomixer (1,000-1,200 rpm) or vortex mixer equipped with multi-tube holder (setting 2-3 on a vortexer with a max intensity of 10 ).

iv. Remove the acidified digest solutions to microcentrifuge tubes ('protein low-binding' optional); hold at room temperature or $4{ }^{\circ} \mathrm{C}$ while pieces are further extracted.

IMPORTANT: Performance may vary, some considerations discussed here (Kraut et al., 2009). Tubes that will be exposed to $40 \%+$ acetonitrile (as below) may benefit from being pre-washed with pure acetonitrile. Some tubes may leak plasticizers or unincorporated (co)polymers when challenged with high concentrations of organic solvents. Some examples of polymer contaminated mass spectra are displayed in LaCava et al., 2015, Figure 5. The best practice is to empirically test your tubes, and 
then repeat these tests periodically (or, when a problem occurs) because occasional (usually unannounced) manufacturing changes may alter performance. Pre-washing reduces the potential for contamination of the sample by components of tube manufacturing by first solubilizing them in e.g., high acetonitrile and removing them with the wash. We routinely use $\sim 100 \mu \mathrm{l}$ acetonitrile to wash $0.65 \mathrm{ml}$ tubes and $\sim 300 \mu \mathrm{l}$ to wash $1.5 \mathrm{ml}$ tubes as a precaution (although it may not always be necessary-testing is advised for any doubt). Tubes we commonly use: Sorenson low binding (e.g., \#11300, \#39640T), Eppendorf Protein LoBind, Eppendorf Safe-lock, Research Products International (e.g., \#145525, \#145530). Importantly, the same rules apply for plastic pipette tips used for handling solvents! Use only high quality, solvent resistant tips. These are also available in low protein binding varieties if desired.

v. Extract with $50 \mu \mathrm{l}$ of $0.1 \%(\mathrm{w} / \mathrm{v})$ TFA at room temperature for $45 \mathrm{~min}$ in a Thermomixer or vortex mixer equipped with multi-tube holder, speed setting as above.

vi. Remove the extractants and combine them with the cognate digest solutions. The total volume may be $\sim 100 \mu \mathrm{l}$ for 15 -well and $\sim 150 \mu \mathrm{l}$ for 10 -well gel plugs.

f. Desalt peptides using OMIX tips $(\mathrm{C} 18,100 \mu \mathrm{l})$ by centrifugation.

IMPORTANT: The manufacturer's protocol stipulates pipette-based desalting. We instead use a centrifugal approach because in our experience loading the samples on top of the C18 bed reduces the possibility of (albeit rare) micro-fragments of polyacrylamide gel (or other debris) remaining in the final desalted fraction-such debris may cause column clogging if applied to the mass spectrometer's liquid chromatography column. This centrifugal approach is also beneficial when many samples are to be processed in parallel. If working with only few samples (as may be the case if assessing the heavy-label incorporation of only 1 or 2 cell cultures) you may implement the manufacturer's pipettebased protocol using the solutions described below-but be mindful of potential debris carryover if column clogging issues are observed.

i. Make the following before starting (solutions modified from manufacturer's instructions; see Recipes). Calculate the amount of each solution needed based on the number of samples to be processed plus $10 \%$ volume.

1) Make adaptors to hold the OMIX tips on top of the $2 \mathrm{ml}$ collecting tubes (to collect waste) or $1.5 \mathrm{ml}$ low binding tubes (to collect elution) during centrifugation steps. See Figure 2. 


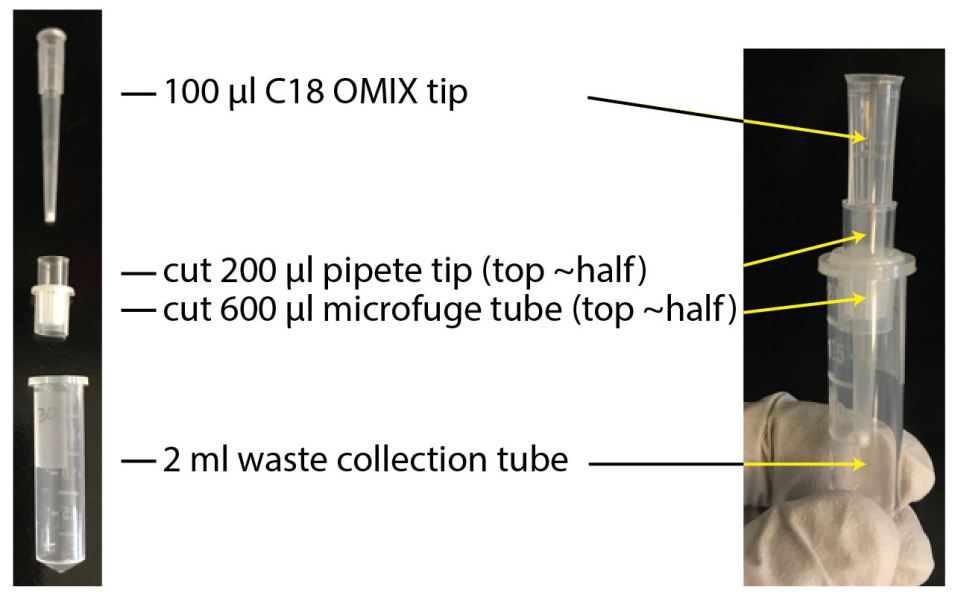

Figure 2. Centrifugal device for solid phase extraction of tryptic peptides for LC-MS/MS.

The individual parts are labeled on the left and shown as assembled on the right.

2) Tip wetting solution: $200 \mu$ per sample.

3) Tip washing solution: $600 \mu \mathrm{l}$ per sample.

4) Elution 1 solution: $80 \mu$ per sample.

5) Elution 2 solution: $80 \mu$ per sample.

6) Carefully label each OMIX tip to help keep track of which sample is loaded on which tip during the following centrifugation steps.

7) Similarly, label a set of clean $1.5 \mathrm{ml}$ low binding tubes (pre-washed with 100\% acetonitrile) for collecting eluted peptides.

8) Put each tip in a $2 \mathrm{ml}$ collecting tube and proceed.

ii. Wet the tips by applying $2 \times 100 \mu$ of tip wetting solution.

1) Add $100 \mu \mathrm{l}$ of wetting solution.

2) Spin at $500 \mathrm{rpm}$ for $1 \mathrm{~min}$ (27 $x \mathrm{~g}$ in an Eppendorf centrifuge 5415).

3) Repeat the two steps above, once.

Note: Check the volume of waste collected during centrifugation steps; make sure that the OMIX tip will not touch the waste in the collecting tube. Aspirate the liquid in the collecting tubes when needed.

iii. Wash tips by applying $2 \times 100 \mu$ l of tip washing solution.

1) Add $100 \mu$ l of washing solution.

2) Spin at $500 \mathrm{rpm}(27 \times \mathrm{g})$ for $1 \mathrm{~min}$.

3) Repeat the two steps above, once.

iv. Bind the samples to $\mathrm{C} 18$ resin.

1) Add the digest solutions from each gel plug $(\geq 100 \mu \mathrm{l})$ to the appropriate OMIX tips. (The tips should accept $\geq 200 \mu \mathrm{l}$.)

2) Spin at $500(27 \times g)$ for $1 \mathrm{~min}$.

3) Check each tip, make sure that the entire sample passes through the filter.

v. Wash the samples by applying $4 \times 100 \mu \mathrm{l}$ of tip washing solution. 
1) Add $100 \mu \mathrm{l}$ of washing solution.

2) Spin at $500 \mathrm{rpm}(27 \times g)$ for $1 \mathrm{~min}$.

3) Repeat the two steps above, three times.

vi. Elute the desalted peptides from the $\mathrm{C} 18$ resin.

1) Transfer the OMIX tips from the $2 \mathrm{ml}$ collecting tubes to the set of $1.5 \mathrm{ml}$ sample collection tubes. (Make sure that the label on the OMIX tip matches the label of the tube.)

2) Elution \#1: apply $80 \mu$ lelution 1 solution to the OMIX tips.

3) Spin at $500 \mathrm{rpm}(27 \times \mathrm{g})$ for $1 \mathrm{~min}$. (Check that all the solution has passed through.)

4) Elution \#2: apply $80 \mu \mathrm{l}$ elution 2 solution to the OMIX tips. Elutions \#1 and \#2 will be collected in the same $1.5 \mathrm{ml}$ tube.

5) Spin at $500 \mathrm{rpm}(27 \times \mathrm{g})$ for $1 \mathrm{~min}$. (Check that all the solution has passed through. Refer to the combined fractions as peptide solutions.)

vii. Put the tubes containing the peptide solutions in a vacuum centrifuge and run until dry. (The time varies by vacuum strength.)

g. Liquid Chromatography Tandem Mass Spectrometry (LC-MS/MS): MS methods will vary depending upon the liquid chromatography (LC) setup, the model of MS instrument, and the operator. We provide the following only as guidelines for conducting shotgun proteomic analyses of affinity enriched samples using an Orbitrap-based hybrid mass spectrometer for LC-MS/MS (Gillet et al., 2016). We typically resuspend our dried samples in $10 \mu \mathrm{l}$ of $0.5 \%(\mathrm{v} / \mathrm{v})$ acetic acid (or, samples are initially concentrated to this volume). On a first run, $\sim 1 / 2$ or preferably $\sim 1 / 3$ of the sample will be loaded onto the LC column for MS analysis (permitting double the quantity to be used in a second run if needed). The column bound peptides are eluted in an acetonitrile gradient (typically reaching $\geq 40 \%(\mathrm{v} / \mathrm{v})$ final concentration of acetonitrile over $\sim 1 \mathrm{~h}$ ), in the presence of an ion pairing reagent such as acetic acid $(0.1 \mathrm{M})$ or formic acid $(0.1 \% \mathrm{v} / \mathrm{v})$ at a flow rate of $200-300 \mathrm{nl} / \mathrm{min}$. Data dependent $\mathrm{MS}^{2}$ fragmentation spectra (e.g., of the top 20 most abundant $\mathrm{MS}^{1}$ ions) are acquired via collision induced dissociation (CID) or high-energy collisional dissociation (HCD). The resulting mass spectra then require processing in a suitable software package to interpret the proteins present as well as relative quantities and specificities thereof.

Note: MaxQuant (Cox and Mann, 2008) is a widely used, freely available MS processing software package with detailed protocols available (Tyanova et al., 2016)-our procedure is summarized below.

h. Data processing: Use MaxQuant to search the raw data against a database of human protein sequences (we typically us a www.uniprot.org fasta file), as well as a decoy database of reversed protein sequences (set in software), with Arg10 and Lys8 as potential heavy labels. Note that although ORF1p and ORF2p are now represented in Uniprot (entries Q9UN81 and O00370, respectively), you may want or need to add custom sequences for ectopically expressed L1s to your database. For the determination of heavy labeling, we do 
not typically use the "re-quantify" option; and a typical result with these settings will identify and quantify $\geq 300$ proteins. The "peptide.txt" output file can be used to calculate the heavy amino acid incorporation (Geiger et al., 2011). Peptides corresponding to known exogenous contaminants such as keratin and trypsin should be removed. Lysine- and argininecontaining peptides are considered separately. The "ratio H/L" for each peptide is converted to $\mathrm{H} /(\mathrm{H}+\mathrm{L})$ using the equation $\mathrm{H} /(\mathrm{H}+\mathrm{L})=$ ("ratio $\mathrm{H} / \mathrm{L}$ ")/(1 + "ratio $\mathrm{H} / \mathrm{L}$ "). The median values of $\mathrm{H} /(\mathrm{H}+\mathrm{L})$ for lysine- and arginine-containing peptides are then obtained. Note, these values underestimate incorporation, as a peptide "ratio $\mathrm{H} / \mathrm{L}$ " cannot be calculated by MaxQuant when there is no detectable signal at the mass-to-charge ratio of the light partner, as would be expected in the case of full incorporation of heavy amino acid. If the average of the median values of the lysine- and arginine-containing peptides is $-95 \%$ or better, it is indicative of thorough heavy labeling and suitability for quantitative comparisons by SILAC.

C. Differential affinity immobilization

1. Production of anti-FLAG magnetic medium. The procedure has been summarized below. We refer the reader to the following references: Cristea and Chait, 2011; Domanski et al., 2012; and Taylor et al., 2016 for comprehensive background on the procedure. Both the Cristea and Chait, and the Taylor et al. references contain detailed step-by-step procedures. However, one may also simply follow the manufacturer's instructions (Thermo Fisher Scientific). Briefly:

a. Prepare $20 \mu \mathrm{l} \mathrm{of} 0.5 \mu \mathrm{g} / \mu \mathrm{l}$ antibody (anti-FLAG M2), in a sodium phosphate ( $\mathrm{pH} 7.4$ ) buffered $1 \mathrm{M}$ ammonium sulfate solution, per $\mathrm{mg}$ of magnetic beads to be antibody-conjugated (i.e., $10 \mu \mathrm{g}$ of antibody, in $20 \mu \mathrm{l}$ solution, will be used per mg of beads).

Note: Millipore Sigma product F1804 contains 50\% glycerol and will need to be buffer exchanged prior to epoxy coupling; product F3165 can be used directly (Domanski et al., 2012).

b. Combine the antibody solution and the magnetic beads and incubate overnight (16-24 h) at $30-37{ }^{\circ} \mathrm{C}$ with rotation. The mixing applied should be sufficient to ensure the beads remain in suspension for the duration of the incubation. For small batches, conjugation can be performed at $37^{\circ} \mathrm{C}$ in a thermomixer ( $\left.\geq 1,200 \mathrm{rpm}\right)$; however, evaporation and the formation of condensate away from the bulk solution should be avoided, so appropriately even heating or sufficiently thorough mixing are required.

c. After coupling, remove the excess antibody solution, wash the beads to remove residual uncoupled antibodies.

Note: You may choose to analyze the antibody depletion during conjugation by running 1-2 $\mu \mathrm{l}$ of the antibody mix before (input) and after (flow-through) the coupling on an SDS-polyacrylamide gel and Coomassie staining.

d. Finally resuspend the antibody-conjugated magnetic medium in 'storage solution' (Recipe B4): add $6.7 \mu \mathrm{l}$ of storage solution per $1 \mathrm{mg}$ of medium (resulting in a slurry of $\sim 15 \% \mathrm{w} / \mathrm{v}$ ) 
and store at $-20^{\circ} \mathrm{C}$. The slurry can be stored in this way for at least 1 year without any noticeable loss of performance.

2. Affinity purification in conjunction with on-the-beads RNase treatment

A general procedure describing and demonstrating best practices for affinity purification using mammalian cell powder and magnetic media has been previously described (LaCava et al., 2016); a procedure specifically for anti-FLAG affinity capture of ORF2p-3xFLAG-tagged L1 RNPs has also been detailed (Taylor et al., 2016); the following implementation has been modified to test the effects of RNase A/T1 treatment on affinity immobilized L1 RNPs. Before carrying out a SILAC-based quantitative MS experiment (described below), preliminary studies should be carried out using general protein staining and Western blotting (e.g., see Figure 4A, and Taylor et al., 2013, Figure 6).

a. Pre-cool a metal spatula and $8 \times 2 \mathrm{ml}$ safe-lock tubes in $\mathrm{LN}_{2}$. An aluminum block style tube rack is helpful for this step.

b. Dispense $4 \times 200 \mathrm{mg}$ of heavy and light HEK-293TLD cell powders, respectively (i.e., 800 $\mathrm{mg}$ total of each), to pre-cooled $2 \mathrm{ml}$ safe-lock tubes.

Note: It is important to keep the cell powder frozen. Leave the tubes in $L N_{2}$ until the next step is initiated.

c. Place the samples in the rack, open the caps, and let them stand at room temperature for $1 \mathrm{~min}$.

d. Add $800 \mu \mathrm{l}$ of room temperature protein extraction solution (see Recipes) to each tube.

e. Vortex at maximum speed to fully resuspend the cell powder (should not require more than $30 \mathrm{~s}$ ), and immediately place the samples on ice.

Note: Once the cell powder is resuspended, the sample should be held on ice between all manipulations throughout the procedure unless otherwise stated.

f. Briefly sonicate, on ice or at $4{ }^{\circ} \mathrm{C}$, to completely disperse and homogenize the cell powder. As a guide, we apply $\sim 15-20 \mathrm{~J}$ energy per $100 \mathrm{mg}$ cell powder extracted with $400 \mu \mathrm{l}$ solution (LaCava et al., 2016).

Note: If clumps are visible, the sonication step should be repeated until no clumps are obvious by visual inspection. Likewise, once extracts appear homogenous upon visual inspection, no further sonication is needed.

g. Clarify the extract by centrifugation at $20,000 \times \mathrm{g}$ for $10 \mathrm{~min}\left(4^{\circ} \mathrm{C}\right)$.

h. While the samples are in the centrifuge, distribute $20 \mu$ anti-FLAG magnetic medium (slurry) into each of the four $2 \mathrm{ml}$ microcentrifuge tubes and wash thrice each with $1 \mathrm{ml}$ of the extraction solution of choice to thoroughly remove the storage solution.

Note: We use $5 \mu \mathrm{l}$ of the beads slurry per $100 \mathrm{mg}$ of the cell powder-this has been titrated for the average expression of ORF2p in our hands, under the preceding conditions. To wash the beads, combine extraction solution with the slurry in a $2 \mathrm{ml}$ microcentrifuge tube and vortex briefly to fully resuspend the beads. Pulse-spin the tube briefly in a mini-centrifuge to collect all the solution at the bottom and then place the tube in a magnetic tube rack until 
the beads are collected at the side of the tube. Remove the supernatant using a pipette or an aspirator and repeat the washing step twice more time. Perform washing steps at room temperature. After washing, the beads may be held on ice and are ready for use.

i. Combine all heavy (with heavy) and light (with light) clarified extracts in $5 \mathrm{ml}$ (or larger) tubes, and then dispense each equally into two new $2 \mathrm{ml}$ tubes containing $20 \mu \mathrm{l}$ anti-FLAG beads resulting in four tubes total: $2 \times 400 \mathrm{mg}$-scale heavy and $2 \times 400 \mathrm{mg}$-scale light ORF2p-3xFLAG affinity isolations.

j. Incubate affinity isolations at $4{ }^{\circ} \mathrm{C}$ for 30 min with end-over-end mixing

k. Wash $3 \times 1 \mathrm{ml}$ extraction solution.

l. Transfer the beads to fresh $1.5 \mathrm{ml}$ tubes during $2^{\text {nd }}$ wash.

$\mathrm{m}$. After removing the final wash, organize the tubes for 4 reactions:

Heavy-untreated: add $50 \mu \mathrm{l}$ of extraction solution $+2 \mu \mathrm{l} 2 \mathrm{mg} / \mathrm{ml} \mathrm{BSA}$

Heavy-treated: add $50 \mu \mathrm{l}$ of extraction solution $+2 \mu \mathrm{l} 2 \mathrm{mg} / \mathrm{ml}$ RNase A/T1

Light-untreated: add $50 \mu \mathrm{l}$ of extraction solution $+2 \mu \mathrm{l} 2 \mathrm{mg} / \mathrm{ml} \mathrm{BSA}$

Light-treated: add $50 \mu \mathrm{l}$ of extraction solution $+2 \mu \mathrm{l} 2 \mathrm{mg} / \mathrm{ml}$ RNase A/T1

$\mathrm{n}$. Incubate the reactions at room temperature for $30 \mathrm{~min}$ with gentle mixing (sufficient to keep the beads suspended: $\sim 1,000 \mathrm{rpm}$ ).

o. Collect the supernatants after $30 \mathrm{~min}$ and save these samples aside. You may choose to analyze them by e.g., analysis by SDS-PAGE (Figure 2A).

p. Wash the beads in each tube with $3 \times 1 \mathrm{ml}$ of ice-cold extraction solution.

q. Elute the materials retained on the affinity medium with $40 \mu \mathrm{l}$ of $1.1 \times$ LDS.

Note: Elution for $10 \mathrm{~min}$ at room temperature with moderate agitation is typically sufficient to thoroughly release 3xFLAG-tagged proteins from anti-FLAG M2 epoxy magnetic beads. However, elution may also be achieved by incubation at $70{ }^{\circ} \mathrm{C}$ for 5 min with moderate agitation-which is more stringent and effective across a wide variety of affinity media. The latter has been observed to mildly increase the co-elution of immunoglobulin chains from anti-FLAG affinity medium prepared as described in this protocol but has not been observed to significantly contribute to eluted protein content: usually IgG chains are observed at only a bit above the limit of detection by Blue Silver stain (estimated in the -1-5 ng range). Immunoglobulin chains release from other media may be drastic under these conditions and should be checked, case-by-case.

r. Samples may be stored at $-20^{\circ} \mathrm{C}$ or colder.

D. Analysis by quantitative MS

1. Combine elution samples as follows:

a. Light-treated with Heavy-treated (RNase light -with- RNase ${ }^{\text {heary; }} 10 \mu \mathrm{l}$ each)

b. Light-untreated with Heavy-untreated (BSA ${ }^{\text {light }}$-with- BSA ${ }^{\text {heavy }} ; 10 \mu \mathrm{l}$ each)

Note: Samples $\boldsymbol{a}$ and $\boldsymbol{b}$ are controls: the expectation is that light and heavy samples should contribute the comparable protein constituents approximately equally to the mixture-i.e., the 
metabolic labeling should not itself affect the result. Most proteins observed in these fractions should be $\sim 50 \%$ heavy-labeled.

c. Light-treated with Heavy-untreated (RNase ${ }^{\text {light }}$-with- BSA ${ }^{\text {heavy; }} 30 \mu \mathrm{l}$ each)

d. Light-untreated with Heavy-treated (BSA light -with- RNase ${ }^{\text {heavy; }} 30 \mu \mathrm{l}$ each)

Notes:

a. Samples $\boldsymbol{c}$ and $\boldsymbol{d}$ are the experimental samples representing label-swapped technical replicates comparing case (RNase) to control (BSA).

b. Small aliquots $(-10 \%)$ of the separate or combined fractions may be set aside for additional cross-checks by SDS-PAGE and staining or Western blotting.

The mixing of samples a-d is displayed schematically in Figure $4 B$ and the resulting SDSpolyacrylamide gel is shown in Figure 4C.

2. Add DTT to $25 \mathrm{mM}$ to all samples and heat at $70{ }^{\circ} \mathrm{C}$ for $10 \mathrm{~min}$, and then briefly chill samples on ice.

3. Add iodoacetamide to $100 \mathrm{mM}$ and incubate at room temperature for $30 \mathrm{~min}$ in the dark.

4. Load sample on a 10 -well, $1 \mathrm{~mm}, 4-12 \%$ Bis-Tris gel.

a. Before assembling the gel in the electrophoresis apparatus, use a ruler to draw a horizontal line across the gel cassette, in indelible marker, at a position $6 \mathrm{~mm}$ below the bottom of the wells.

b. Samples $\mathbf{c}$ and $\mathbf{d}$ will be $\sim 70 \mu \mathrm{l}$ each and may be loaded in two rounds into the same well if needed. First load $40 \mu \mathrm{l}$ and apply $200 \vee$ until the whole sample enters the gel ( $\sim 30 \mathrm{~s}-1$ min). Now load the remaining sample. Carefully layer the sample at the very bottom of the well using a gel-loading tip; residual glycerol in the well from the first loading will prevent the subsequent sample from "falling" into the well, so layering from the bottom of the well is crucial during the second round of sample loading.

5. Electrophorese until all the loading dye reaches the $6 \mathrm{~mm}$ mark and stain (see Figure 4C), as per Step B3b (above).

6. Excise gel plugs, and process as per Steps B3c to B3f (above).

7. LC-MS/MS as per Step B3g (above)

Details of the MS run as we conducted it are as follows: $\sim 3 \mu \mathrm{l}$ (i.e., $1 / 3^{\text {rd }}$ ) were injected per LCMS/MS analysis. Samples were loaded onto a PicoFrit column (New Objective, Woburn, MA) packed in-house with $6 \mathrm{~cm}$ of reverse-phase C18 material (YMC*Gel ODS-A, YMC, Allentown, $P A$ ). Peptides were gradient-eluted (Solvent $A=0.1 \mathrm{M}$ acetic acid, Solvent $B=0.1 \mathrm{M}$ acetic acid in $70 \% \mathrm{v} / \mathrm{v}$ acetonitrile, flow rate $200 \mathrm{nl} / \mathrm{min}$ ) into an LTQ-Orbitrap-Velos (Thermo Fisher Scientific) acquiring data-dependent CID fragmentation spectra.

\section{Data analysis}

1. Initial data processing in MaxQuant 
a. Searches were performed against human protein sequences (UP000005640, April 2016) supplemented with custom L1 ORF1p and ORF2p protein sequences, common exogenous contaminants, and a decoy database of reversed protein sequences.

Search parameters included:

i. Fixed modification: carbamidomethyl (C).

ii. Variable modifications: Arg10, Lys8, methionine oxidation.

iii. Razor and unique peptides used for protein quantitation.

iv. Requantify: enabled.

b. Contaminants, low-scoring proteins, and proteins with only one razor + unique peptide were filtered out from the MaxQuant output file 'proteingroups.txt'. The list of contaminants was uploaded from the MaxQuant website (http://www.coxdocs.org/; 'contaminants'). Additionally, proteins with the 'POTENTIAL CONTAMINANT' column value '+' were filtered out.

c. Proteins with at least two razor+unique peptides were retained for the analysis. $\mathrm{H} /(\mathrm{H}+\mathrm{L})-$ i.e., \% heavy - and $\mathrm{L} /(\mathrm{H}+\mathrm{L})-$-i.e., \% light - values were derived from unnormalized 'ratio $\mathrm{H} / \mathrm{L}^{\prime}$ values and were used in post-processing (below) prior to plotting the label-swapped RNase-sensitivity, shown in Figure 4D.

2. Custom post-processing

a. The RNase sensitivity data obtained from MaxQuant were rescaled and normalized such that proteins that did not change upon treatment with RNases were centered at the origin and those that were completely sensitive would give a value of 1.0. In a perfect experiment, unchanging proteins would yield a ratio of 0.5 when comparing the fraction of each protein present in the BSA-treated sample to the sum of both the BSA- and RNase-treated samples; i.e., $1 /(1+1)$. However, our data exhibit some variability, as shown in Figure 3A. Therefore, we normalized the data such that the peaks were re-centered at 0.5 . From this set, 0.5 was subtracted from the data (centering insensitive proteins at the origin, and completely sensitive proteins at 0.5 ), followed by multiplication by two to expand the data to cover the range from 0 (insensitive) to 1 (completely sensitive); these latter two transformations are encompassed by the functions:

$g(x)=x+b$, and $f[g(x)]=a(x+b)$

where, $a=2 ; b=-0.5$.

b. To determine if these data were normally distributed the distances from the $(0,0)$ point to protein coordinates were calculated. Proteins with distance less than two median distances were selected. The Shapiro-Wilk normality test (the null-hypothesis of this test is that the population is normally distributed) was applied for the distances $(P$-value $=0.29)$. The distribution of the distances was plotted as a histogram displaying the frequency ( $y$-axis) 
versus RNase sensitivity (x-axis) of a simulation of normally distributed data (shown in black) and the actual data shown in blue; a Q-Q plot was also drawn-both displayed in Figure 3B.

c. The mean value and standard deviation were calculated using the distribution of distances from the origin. The distance threshold for $P$-value $=0.001$ was calculated using the $R$ programming language. A circle with radius equal to the threshold was plotted and points with distances higher than the threshold were marked as black (Figure 2D).

d. The relevant code for the above post-processing can be obtained here: https://bitbucket.org/altukhov/line-1/src/master/src/protein analysis/RNAse.R

A

Re-centering data

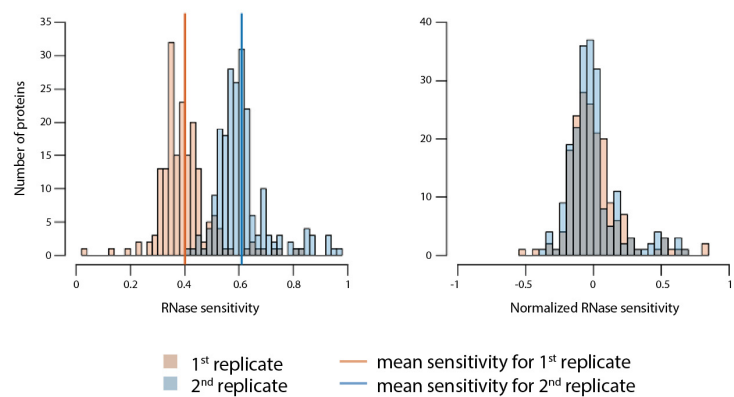

B

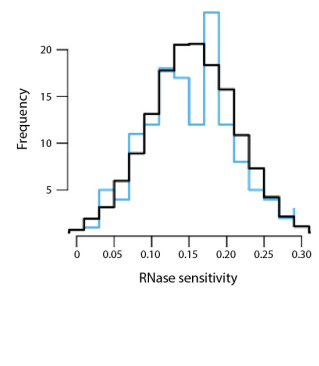

Normality tests

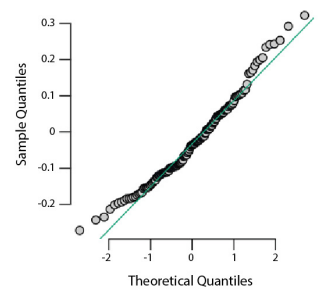

Figure 3. Data treatment. A. Data re-centering as described in step 2a (Data analysis). B. Normality tests as described in step $2 \mathrm{~b}$ (Data analysis). This figure reproduced from/modified from Taylor et al. (2018).

The prior I-DIRT analysis (Taylor et al., 2013) is an important aspect of the presented analysis. SILAC as conducted here-so-called mix after purification or MAP-SILAC (Wang and Huang, 2008)does not reveal any information about which interactions are specific or non-specific; it only reveals what has changed between the two treatments (with RNases or BSA). We used I-DIRT, first, in order to establish which interactions are likely to have formed in vivo, versus which are likely to be post-extraction in vitro artifacts (Tackett et al., 2005). Importantly, the I-DIRT data was collected using comparable experimental conditions (i.e., protein extraction and affinity capture parameters) as for the SILAC data. By using the I-DIRT analysis as a specificity filter on the SILAC analysis, second, we were able to focus our attention on the differential behaviors of proteins most likely to be bona fide physical interactors within L1 RNPs (colored nodes, Figure 4D). Nevertheless, the proteins that were RNase sensitive and not I-DIRT-specific (black nodes, Figure 4D) proved informative: they are all RNA-binding proteins that one might expect to be released by RNase treatment. Thus, they served as a secondary indicator that the treatment is effective. Notably, PABPC1 and C4-poly(A) RNA binding proteins appear insensitive to RNase treatment. This is most likely due to the fact that neither RNase A nor T1 cleave RNA at adenosine residues (Volkin and Cohn, 1953; Yoshida, 2001); hence poly(A) binding proteins may not be ready targets for release 
from direct RNA binding by the assay implemented here (or generally, using these ribonucleases) - see further discussion in (Taylor et al., 2018). On the basis of these data, we concluded that UPF1, ZCCHC3, MOV10, and ORF1p are at least partly dependent upon the presence of intact RNA to remain stably associated within L1 RNPs.

A
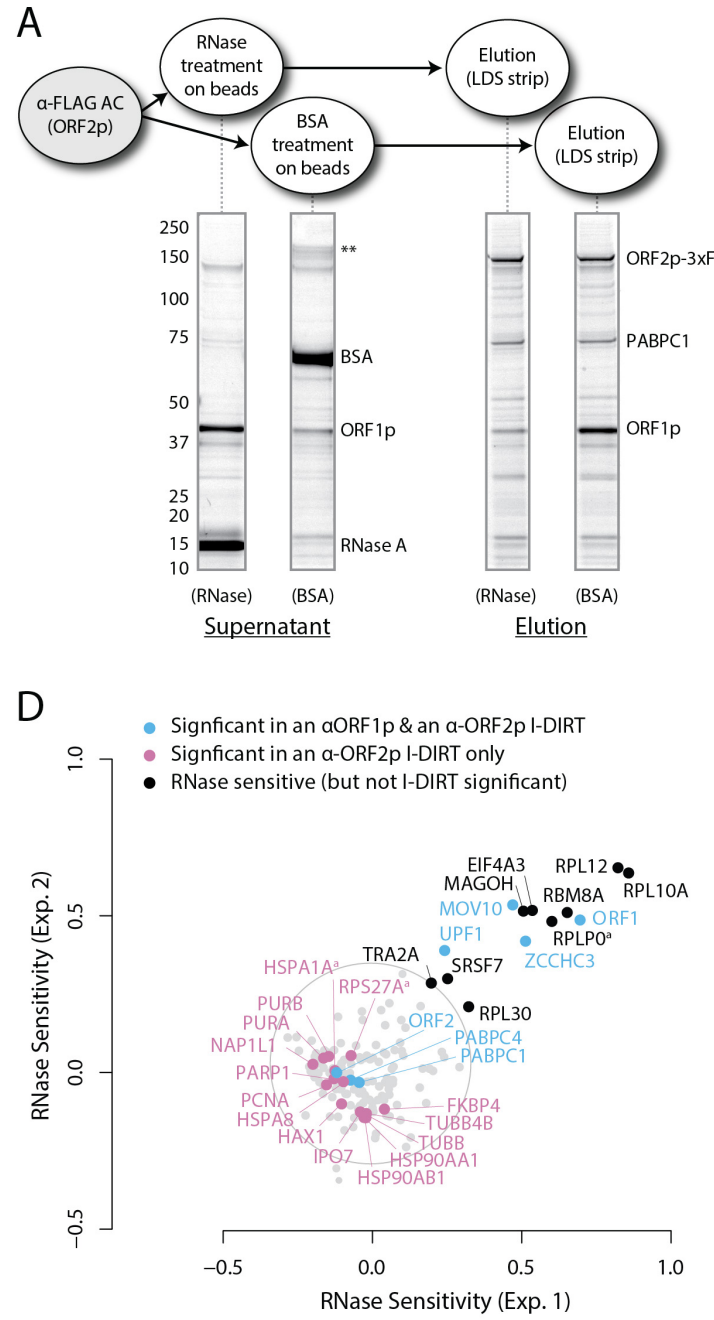

B

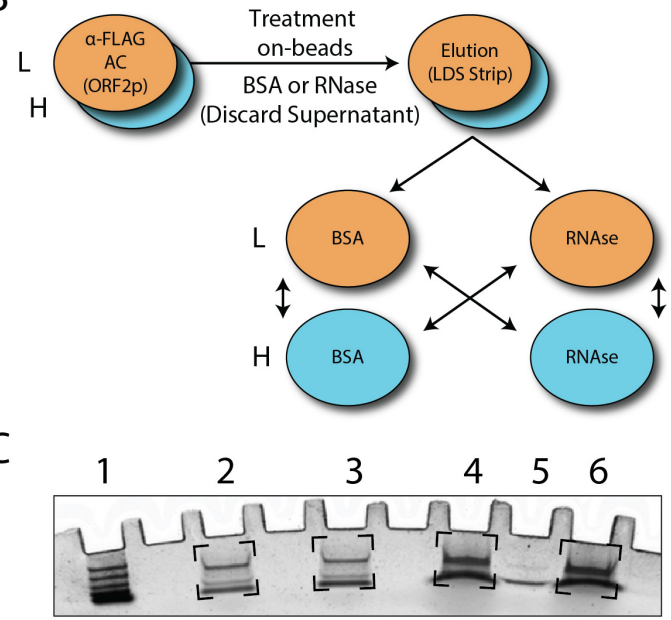

Figure 4. RNase sensitivity affinity capture (modified from Taylor et al., 2018). A. Coomassie Blue G-250 stained SDS-polyacrylamide gel displaying the profiles of the RNase- or BSA-treated affinity immobilized fractions. This kind of gel would be run during preliminary studies of RNase (or other enzyme) treatments. Major changes can be observed visually. If the identities of bands visually observed change upon RNase treatment are not know, they may be cut from e.g., the RNase supernatant lane (far left) and BSA elution lane (far right) and analyzed by mass spectrometry. More, subtle potential differences may be monitored by Western blotting. B. Mixing scheme for light and heavy SILAC-labeled fractions, as described in Step D1. C. Example image of Coomassie Blue G250 stained gel plugs resulting from Step D5. Brackets indicate the gel areas excised and prepared for analysis. (1) Molecular mass marker. (2) Light-treated with Heavy-treated (RNaselight - withRNase $^{\text {heavy }}$ ). (3) Light-untreated with Heavy-untreated (BSA ${ }^{\text {light }}$-with- BSA ${ }^{\text {heavy }}$ ). (4) Light-treated with 
Heavy-untreated (RNase light -with- BSA ${ }^{\text {heavy }}$ ). (5) BSA-200 ng. (6) Light-untreated with Heavytreated (BSA ${ }^{\text {light }}$-with- RNase ${ }^{\text {heavy }}$ ). D. Processed data displaying the degree of RNase-sensitivity (i.e., differential affinity immobilization) exhibited by constituents of the SILAC-labeled fractions. Proteins requiring intact RNA to maintain stable interactions with immobilized ORF2 $p$ were released from the RNase-treated medium, while the BSA-treated sample controlled for the spontaneous release of proteins from the medium. Results from the assay have been graphed as the fraction of each detected protein present in the BSA-treated sample (RNase-sensitive proteins are more present in the BSA treated sample), normalized as described in step 2 (Data analysis). A cut-off of $P=10^{-3}$ for RNase-sensitivity is indicated by a light gray circle; proteins that are RNase-sensitive with a statistical significance of $P<10^{-3}$ are outside the circle. Proteins previously ranked significant by I-DIRT analysis (Taylor et al., 2013) are labeled and displayed in blue or magenta (as indicated); black nodes were RNase-sensitive but not significant by I-DIRT; gray, unlabeled nodes were neither RNase-sensitive nor significant by I-DIRT.

\section{Recipes}

A. Cell culture media

Note: Phenol red (final $0.001 \% \mathrm{~W} / \mathrm{V}$ ) may be added as a $\mathrm{pH}$ indicator. Antibiotics and/or antimycotics are not recommended in combination with PEI-based transfection; the combination of PEI and penicillin-streptomycin reduces cell viability and transfection efficiency. Most of our cultures are antibiotic free. Although the Freestyle-293 medium is designed to be used serum-free with the manufacturer's cell lines, we have seen reduced growth rates and low viability at FBS below 1\% ( V/V) for HEK-293T LD and other 293 cells.

1. Heavy SILAC medium

Supplement Freestyle-293 medium lacking arginine and lysine with:

$1 \%$ v/v dialyzed FBS

2 mM L-glutamine

$200 \mathrm{mg} / \mathrm{L} \mathrm{L}$-proline

$800 \mathrm{mM}{ }^{13} \mathrm{C}_{6}{ }^{15} \mathrm{~N}_{4}$-L-arginine (Arg10)

$400 \mathrm{mM}^{13} \mathrm{C}_{6}{ }^{15} \mathrm{~N}_{2}$-L-lysine (Lys8)

2. Light SILAC medium

Supplement Freestyle-293 medium lacking arginine and lysine with:

$1 \%$ v/v dialyzed FBS

2 mM L-glutamine

$200 \mathrm{mg} / \mathrm{L} \mathrm{L}$-proline

$800 \mathrm{mM}$ L-arginine

400 mM L-lysine 
B. Magnetic bead coupling solutions

1. 10x PBS stock solution

$3.1 \mathrm{~g}$ of $\mathrm{NaH}_{2} \mathrm{PO}_{4} \cdot \mathrm{H}_{2} \mathrm{O}, 10.9 \mathrm{~g}$ of $\mathrm{Na}_{2} \mathrm{HPO}_{4}$, and $87.8 \mathrm{~g} \mathrm{NaCl}$ per liter; the final $\mathrm{pH}$ should be 7.4, confirm with $\mathrm{pH}$ indicator paper

A $1 \times$ solution yields $\sim 10 \mathrm{mM}$ phosphate, $150 \mathrm{mM} \mathrm{NaCl}$ at $\mathrm{pH} 7.4$

2. $\quad 0.1 \mathrm{M}$ sodium phosphate $\mathrm{pH} 7.4$

Follow a standard phosphate buffer chart, or e.g., add $3.1 \mathrm{~g}$ of $\mathrm{NaH}_{2} \mathrm{PO}_{4} \cdot \mathrm{H}_{2} \mathrm{O}$ and $10.9 \mathrm{~g}$ of $\mathrm{Na}_{2} \mathrm{HPO}_{4}$ (anhydrous) to distilled $\mathrm{H}_{2} \mathrm{O}$ to make a volume of $1 \mathrm{~L}$

The $\mathrm{pH}$ of the final solution will be 7.4-confirm with $\mathrm{pH}$ indicator paper

3. $3 \mathrm{M}$ Ammonium Sulfate

$39.6 \mathrm{~g}\left(\mathrm{NH}_{4}\right)_{2} \mathrm{SO}_{4}$ combined with $0.1 \mathrm{M}$ sodium phosphate $\mathrm{pH} 7.4$ to a final volume of $100 \mathrm{ml}$

4. Magnetic Media Storage Solution

1x PBS [final] containing $0.5 \mathrm{mg} / \mathrm{ml} \mathrm{BSA}$ and $50 \%(\mathrm{v} / \mathrm{v})$ glycerol

C. Protein extraction, staining, and destaining solutions

1. Protein extraction solution

20 mM HEPES-Na pH 7.4

$1 \%(\mathrm{v} / \mathrm{v})$ Triton X-100

$500 \mathrm{mM} \mathrm{NaCl}$

Note: This solution is supplemented with protease inhibitors during protein extraction and is used without the addition of protease inhibitors during subsequent washes of the affinity medium. The frozen cell powders should be extracted with a room temperature solution, resulting in cold extracts that are subsequently handled on ice and/or at $4{ }^{\circ} \mathrm{C}$; for subsequent washes of the affinity medium, after protein capture, the solution should be ice-cold.

2. Gel acidification solution

$0.1 \mathrm{M} \mathrm{HCl}$

3. Blue Silver Stain (modified from Candiano et al., 2004)

$20 \%(w / v) \mathrm{H}_{3} \mathrm{PO}_{4}$

$10 \%(\mathrm{w} / \mathrm{v})\left(\mathrm{NH}_{4}\right)_{2} \mathrm{SO}_{4}$

0.12\% (w/v) Coomassie Brilliant Blue G-250

$20 \%(\mathrm{v} / \mathrm{v})$ methanol

a. To water $\left(1 / 10^{\text {th }}\right.$ of the final volume), add first the phosphoric acid (we use double the published quantity). Note, commercially available concentrated phosphoric acid tends to be prepared at $\sim 85 \%$ (w/w) with a density of $\sim 1.69 \mathrm{~g} / \mathrm{ml}$.

b. Next, add the ammonium sulfate. When the ammonium sulfate has dissolved (incrementally add more water if this is taking excessively long), add the G-250 dye, and bring the water to $80 \%$ of the final volume.

c. To this solution, under vigorous stirring, add anhydrous methanol to $20 \%$ the final volume; once the solution is thoroughly mixed, adjust it to the final volume with water. 
d. This solution should be kept in a brown or foil-covered bottle and is stable at room temperature for 6 months.

4. Gel plug destaining solution

$50 \mathrm{mM}$ ammonium bicarbonate in 50\% (v/v) acetonitrile, prepared in LC-MS grade water

Example: Combine one part $100 \mathrm{mM}$ ammonium bicarbonate in LC-MS grade water with one part LC-MS grade acetonitrile. Prepare this solution fresh before use. One-hundred millimolar ammonium bicarbonate yields a solution of $\mathrm{pH} \geq 8.5 ; 50 \mathrm{mM}$ ammonium bicarbonate should produce a solution of $\mathrm{pH} \sim 8$.

D. OMIX C18 tip, peptide desalting solution

1. Tip wetting solution

$0.1 \%(w / v)$ TFA

$50 \%(\mathrm{v} / \mathrm{v})$ acetonitrile

$200 \mu$ l per sample

2. Tip wash solution

$0.1 \%(w / v)$ TFA

$600 \mu$ l per sample

3. Elution 1 solution

$0.5 \%(\mathrm{v} / \mathrm{v})$ acetic acid

$40 \%(\mathrm{v} / \mathrm{v})$ acetonitrile

$80 \mu \mathrm{l}$ per sample

4. Elution 2 solution

$0.5 \%(\mathrm{v} / \mathrm{v})$ acetic acid

$80 \%(\mathrm{v} / \mathrm{v})$ acetonitrile

$80 \mu \mathrm{l}$ per sample

\section{Acknowledgments}

We thank Professors Michael P. Rout, Brian T. Chait, Jef D. Boeke, and David Fenyö for their invaluable support of our research. This work was supported in part by the National Institutes of Health grants R01GM126170 and P41GM109824.

\section{Competing interests}

The authors declare no conflicting or competing interests. 


\section{References}

1. An, W., Dai, L., Niewiadomska, A. M., Yetil, A., O'Donnell, K. A., Han, J. S. and Boeke, J. D. (2011). Characterization of a synthetic human LINE-1 retrotransposon ORFeus-Hs. Mob DNA 2(1): 2.

2. An, W., Davis, E. S., Thompson, T. L., O'Donnell, K. A., Lee, C. Y. and Boeke, J. D. (2009). Plug and play modular strategies for synthetic retrotransposons. Methods 49(3): 227-235.

3. Armean, I. M., Lilley, K. S. and Trotter, M. W. (2013). Popular computational methods to assess multiprotein complexes derived from label-free affinity purification and mass spectrometry (APMS) experiments. Mol Cell Proteomics 12(1): 1-13.

4. Candiano, G., Bruschi, M., Musante, L., Santucci, L., Ghiggeri, G. M., Carnemolla, B., Orecchia, P., Zardi, L. and Righetti, P. G. (2004). Blue silver: a very sensitive colloidal Coomassie G-250 staining for proteome analysis. Electrophoresis 25(9): 1327-1333.

5. Cristea, I. M. and Chait, B. T. (2011). Conjugation of magnetic beads for immunopurification of protein complexes. Cold Spring Harb Protoc. doi:10.1101/pdb.prot5610.

6. Cox, J. and Mann, M. (2008). MaxQuant enables high peptide identification rates, individualized p.p.b.-range mass accuracies and proteome-wide protein quantification. Nat Biotechnol 26(12): 1367-1372.

7. Dai, L., Taylor, M. S., O'Donnell, K. A. and Boeke, J. D. (2012). Poly(A) binding protein C1 is essential for efficient L1 retrotransposition and affects L1 RNP formation. Mol Cell Biol 32(21): 4323-4336.

8. Domanski, M. and LaCava, J. (2017). Affinity purification of the RNA degradation complex, the exosome, from HEK-293 cells. Bio-protocol 7(8): e2238.

9. Domanski, M., Molloy, K., Jiang, H., Chait, B. T., Rout, M. P., Jensen, T. H. and LaCava, J. (2012). Improved methodology for the affinity isolation of human protein complexes expressed at near endogenous levels. Biotechniques 0(0): 1-6.

10. Freshney, R. I. (2011). Culture of animal cells. 6th edition. John Wiley \& Sons.

11. Geiger, T., Wiśniewski, J. R., Cox, J., Zanivan, S., Kruger, M., Ishihama, Y. and Mann M. (2011). Use of stable isotope labeling by amino acids in cell culture as a spike-in standard in quantitative proteomics. Nat Protoc 6(2): 147-57.

12. Gillet, L. C., Leitner, A. and Aebersold, R. (2016). Mass spectrometry applied to bottom-up proteomics: entering the high-throughput era for hypothesis testing. Annu Rev Anal Chem (Palo Alto Calif) 9(1): 449-472.

13. Gossen, M., Freundlieb, S., Bender, G., Muller, G., Hillen, W. and Bujard, H. (1995). Transcriptional activation by tetracyclines in mammalian cells. Science 268(5218): 1766-1769.

14. Kimura, M., Takatsuki, A. and Yamaguchi, I. (1994). Blasticidin S deaminase gene from Aspergillus terreus (BSD): a new drug resistance gene for transfection of mammalian cells. Biochim Biophys Acta 1219(3): 653-659. 
15. Kraut, A., Marcellin, M., Adrait, A., Kuhn, L., Louwagie, M., Kieffer-Jaquinod, S., Lebert, D., Masselon, C. D., Dupuis, A., Bruley, C., Jaquinod, M., Garin, J. and Gallagher-Gambarelli, M. (2009). Peptide storage: are you getting the best return on your investment? Defining optimal storage conditions for proteomics samples. J Proteome Res 8(7): 3778-3785.

16. LaCava, J., Jiang, H. and Rout, M. P. (2016). Protein complex affinity capture from cryomilled mammalian cells. $J$ Vis Exp (118): e54518.

17. LaCava, J., Molloy, K. R., Taylor, M. S., Domanski, M., Chait, B. T. and Rout, M. P. (2015). Affinity proteomics to study endogenous protein complexes: pointers, pitfalls, preferences and perspectives. Biotechniques 58(3): 103-119.

18. Longo, P. A., Kavran, J. M., Kim, M. S. and Leahy, D. J. (2013). Transient mammalian cell transfection with polyethylenimine (PEI). Methods Enzymol 529: 227-240.

19. Muller, N., Girard, P., Hacker, D. L., Jordan, M. and Wurm, F. M. (2005). Orbital shaker technology for the cultivation of mammalian cells in suspension. Biotechnol Bioeng 89(4): 400406.

20. O'Donnell, K. A., An, W., Schrum, C. T., Wheelan, S. J. and Boeke, J. D. (2013). $\underline{\text { Controlled }}$ insertional mutagenesis using a LINE-1 (ORFeus) gene-trap mouse model. Proc Natl Acad Sci U S A 110(29): E2706-2713.

21. Okerman, L., Van Hende, J. and De Zutter, L. (2007). Stability of frozen stock solutions of betalactam antibiotics, cephalosporins, tetracyclines and quinolones used in antibiotic residue screening and antibiotic susceptibility testing. Anal Chim Acta 586(1-2): 284-288.

22. Olson, B. J. and Markwell, J. (2007). Assays for determination of protein concentration. Curr Protoc Protein Sci 48: 3.4.1-3.4.29.

23. Ong, S. E., Blagoev, B., Kratchmarova, I., Kristensen, D. B., Steen, H., Pandey, A. and Mann, M. (2002). Stable isotope labeling by amino acids in cell culture, SILAC, as a simple and accurate approach to expression proteomics. Mol Cell Proteomics 1(5): 376-386.

24. Ostertag, E. M., Prak, E. T., DeBerardinis, R. J., Moran, J. V. and Kazazian, H. H., Jr. (2000). Determination of L1 retrotransposition kinetics in cultured cells. Nucleic Acids Res 28(6): 14181423.

25. Shevchenko, A., Tomas, H., Havlis, J., Olsen, J. V. and Mann, M. (2006). In-gel digestion for mass spectrometric characterization of proteins and proteomes. Nat Protoc 1(6): 2856-2860.

26. Stuible, M., Burlacu, A., Perret, S., Brochu, D., Paul-Roc, B., Baardsnes, J., Loignon, M., Grazzini, E. and Durocher, Y. (2018). Optimization of a high-cell-density polyethylenimine transfection method for rapid protein production in CHO-EBNA1 cells. $J$ Biotechnol 281: 39-47.

27. Tackett, A. J., DeGrasse, J. A., Sekedat, M. D., Oeffinger, M., Rout, M. P. and Chait, B. T. (2005). I-DIRT, a general method for distinguishing between specific and nonspecific protein interactions. J Proteome Res 4(5): 1752-1756.

28. Taylor, M. S., Altukhov, I., Molloy, K. R., Mita, P., Jiang, H., Adney, E. M., Wudzinska, A., Badri, S., Ischenko, D., Eng, G., Burns, K. H., Fenyo, D., Chait, B. T., Alexeev, D., Rout, M. P., Boeke, 
J. D. and LaCava, J. (2018). Dissection of affinity captured LINE-1 macromolecular complexes. Elife 7: e30094.

29. Taylor, M. S., LaCava, J., Dai, L., Mita, P., Burns, K. H., Rout, M. P. and Boeke, J. D. (2016). Garcia-Peréz, J. L. (Ed.). Characterization of L1-ribonucleoprotein particles. In: Methods in Molecular Biology. Springer New York. 1400: 311-338.

30. Taylor, M. S., LaCava, J., Mita, P., Molloy, K. R., Huang, C. R., Li, D., Adney, E. M., Jiang, H., Burns, K. H., Chait, B. T., Rout, M. P., Boeke, J. D. and Dai, L. (2013). Affinity proteomics reveals human host factors implicated in discrete stages of LINE-1 retrotransposition. Cell 155(5): 1034-1048.

31. Tyanova, S., Temu, T. and Cox, J. (2016). The MaxQuant computational platform for mass spectrometry-based shotgun proteomics. Nat Protoc 11(12): 2301-2319.

32. Uphoff, C. C. and Drexler, H. G. (2013). Basic cell culture protocols. 4th edition. In: Helgason, C. D. and Miller, C. L. (Eds.). Humana Press.

33. Volkin, E. and Cohn, W. E. (1953). On the structure of ribonucleic acids. II. The products of ribonuclease action. J Biol Chem 205(2): 767-782.

34. Wang, X. and Huang, L. (2008). Identifying dynamic interactors of protein complexes by quantitative mass spectrometry. Mol Cell Proteomics 7(1): 46-57.

35. Yoshida, H. (2001). The ribonuclease T1 family. Methods Enzymol 341: 28-41.

36. Zor, T. and Selinger, Z. (1996). Linearization of the Bradford protein assay increases its sensitivity: theoretical and experimental studies. Anal Biochem 236(2): 302-308. 